\title{
Introduction. Post-Mao, Post-Bourdieu: Class Culture in Contemporary China
}

\author{
Stephanie Hemelryk Donald, RMIT University, \\ Yi Zheng, University of Sydney.
}

This special issue of Portal Journal of Multidisciplinary International Studies explores the relationship between taste, choice and social stratification in contemporary China. It is premised on the observation that the past thirty years of accelerated Reform policies have initiated a system of authoritarian capitalism, which fosters a network of social values, focussed on opportunity and struggle figured through financial achievement and consumption, and given affective meaning through nationalism. Not all Chinese enjoy the full gamut of these experiences, although most partake in struggle in some form. Opportunity arises mainly from the cultural capital, financial and social position of one's parents, and, to some degree, from innate talent and hard work, an urban upbringing, and national provisions for educational advantage. Pre-existing forms of influence and power-local networks, Party membership, sufficient funds for education - are the strongest determinants of sustained success. In some cases, the opportunity for wealth creation has allowed some social mobility for entrepreneurial minds, whilst also re-establishing privilege amongst those whose status was already high through long term political or intellectual activity.

Our research interviews in Sichuan and Guangzhou in 2005-2007 suggested that those who responded to the description xiaokang (well off) ranged from multi-millionaires, to couples with an architect designed home and access to expensive education for their child, to those who had scraped together enough to purchase an apartment in the city,

PORTAL Journal of Multidisciplinary International Studies, vol. 6, no. 2, July 2009.

Post-Mao, Post-Bourdieu: Class and Taste in Contemporary China, Special Issue, guest edited by Yi Zheng and Stephanie Hemelryk Donald. 
and perhaps a car. At the same time, cheap labour, domestic migration flows, the disestablishment of state owned enterprises and the welfare net that they represented, have thrust millions into uncertainty and the particular poverty of a precarious client relationship with the marketised State.

Although the actual economics of status are not the main focus of this special issue, they are of course crucial to the conditions through which a newly forming idea of class, if not class itself, is managed and performed. In all of these discussions it is important to bear in mind that status does not necessarily translate into fixed class positions, but that class is generally characterised in part by high or low status. We are interested here not just in how an idea of class is made and unmade by wealth and relative poverty, but how it is claimed and reproduced through the actions of the State and of individuals, or indeed bypassed by short term self interest. Arguably, the absence of clearly defined class categories and attendant class interest groups and strategies makes the status seeking behaviour of Chinese elites, middle-income workers and the working poor even more important. One hypothesis for China's idea of class might be that status is the end point of consumer endeavour, and that self-interest has deferred class interest. Further, the rise of nationalism and the central policy of harmonisation allow this deferral to continue, with the social energies of the people being deflected into larger scales of rhetorical belonging. Our question then might be: will the practice of taste differentiation gradually create mutually acknowledged social groups and relations, or is consumption hiding a chaotic and atomistic meltdown of the social and political order?

Using the terminology of class is therefore vexed, and slippages occur easily. Erik Wright Olins has recently acknowledged that class is usefully theorised (in three traditions) vis-a-vis social position and economic opportunity, power and exploitation, materiality access and behaviour (2009: 102). All are relevant to the Chinese case, although we also suggest that class may be elided by the presumption of the State's interests, even as these processes continue.

A way into this conundrum might be to consider the degree to which class consciousness is at work in socio-political interactions. There are certainly levels of attainment and privilege in China, which are based on birth opportunity more than on inherent merit. Provincial origin and immediate family background still matter in one's life chances. The poor are many and various however; if there is class consciousness 
among them, it is sporadic and localised. There are also those who are not poor as such; they have average expectations for themselves and their children, and they might in other contexts be defined as working class. Now, they are inevitably caught up in the aspirational culture of a consumer driven urban market - which in turn determines the nature of their struggle and opportunity, and which also dissipates class interests in favour of the immediacy of adaption and survival. There are the well off, the rich, and the super-rich, and their sense of class is stronger insofar as they both understand their exposure to instability both politically and financially, and are able to work politically to protect themselves. Their grouping, the articulate elites in Reform China, is more an act of organisational will by the leadership of the Party than it is an organic achievement of the market, and these upper/middle populations are thus vulnerable to shifts in politics as well as to the vagaries of global finance.

This last group is frequently lumped together as the new middle classes of China, a misnomer that nonetheless has purchase overseas, and that serves at home to 'vanish' real class description and potential from the political field. 'When we speak of the 'Chinese middleclass,' to whom and to what do we refer?' asks Doctoroff, in his bestseller guide to marketing in China, Billions: Selling to the New Chinese Consumer (2005: 14). It is a question that is asked frequently in developed economies, as China's new business partners look for points of familiarity to reconcile their worldview to the shift in global power. Whether or not the question is a reasonable one, it persists. The answer, for Doctoroff, is the populations referred to previously as the xiaokang, those who are enjoying increased wealth in urban areas, and whose class practices are rhetorically aligned to the key growth strategy of the Chinese Communist Party. Postreform affluence is in line with the blueprint for a future China launched by the Sixteenth-Congress of the Chinese Communist Party held in November 2002. There, the 'parlance of the Sixteenth People's Congress ... wink [ed] at a robust, yet pliable, xiao kang (relatively wealthy) society' (Doktoroff 2005: 14). China's future would be built on the construction and stabilisation of a comprehensive 'relatively affluent (xiaokang) society,' with the understanding that over time there would be a steady increase in the national ratio of middle-income earners to the poor, thus marrying growth to social harmonisation. So, in defining middle class-ness in China, Doctoroff describes a policy situation that defuses class interests in favour of a national interest strategy described by state capitalism and authoritarian developmentalism. The idea of middle-class-ness is an 
anti-class deployment of status and economic survival for a large minority. The voices of the well-off, the wealthy and the rich combine to drown out the voices of the poor, whilst promising a nationally inspired parity for everyone. Again a paradox, it is the exploitation model of class used to deny class division at the level of the nation's selfimage.

\section{The new utopia}

The Party's vision of a harmonious xiaokang one-class/no-class society responds to the need to consolidate and harness the successes of the economic reform, and addresses the traumatic social differentiations that have been caused in the process. 'Harmonious society' promises redress, over time, for the increasing gap between the rich and poor. In this sense the Chinese middleclass-to-be is similar to the new middle classes of other areas of recent affluence in Asia, described by Stivens as 'the children of these hypertrophic states' (1998: 13). They are both real and important, but not quite what they are made out to be in the political rhetoric of the State. These are not the middle classes in the sense that they are challenging a ruling class; they are rather commanded and compounded as a legitimising product and constituent of the ruling elite's political and economic power. The inclusion of their relative success is crucial to the narrativisation of China's economic miracle.

The rhetorical insistence on harmonising economic disparity and social difference reveals both political anxiety and a new Utopian vision. In some quarters, it reinvokes the spectre of old-style class conflict, which has been the cause and subject of deeply violent episodes over the past century. Elsewhere, this 'wink' at class opens up new commercial and personal opportunities. It promises access to the dollars of economic reform, through a newly mobile social field and competitive cultural aspirations.

Different urban and provincial environments, and alternative developmental rates and opportunities are obvious but not theorised in Party rhetoric. The Chinese middleclass(es) as an idea is thus an approximate vision of the new Chinese Utopia. While in popular, especially commercially driven, representation it is often used to signal 'all that is desirable and tasteful in life' (Chen \& Yi 2004: 1), politically it is spelled out as a foundational project by the leaders of State-Planning Bureaux. In a forum called 'Cutting-Edge Academic Discussions' in Beijing 2002, for example, the Vice-Director of the State Bureau for Statistics He Ken stated that 'middleclass' should 
signify 'relative affluence' and 'civilised.' It should be a social stratum that will form the mainstay of the citizens of a future Chinese xiaokang society. As leading members of a 'relatively affluent' future China, he further elaborates, the middle class should be not only economically well off, but also high in spiritual-cultural quality (jingshen wenhua suzhi).

Middle-class-making, as the foundational project for post-reform affluent China, not only depends on State-led economic development, but also involves normative cultural practices which necessitate the active participation of the State and society at large, from the economic sectors to individual aspirants. Taste is thus allied to social value and in turn to the harmonisation of cultural and political behaviours.

\section{Post-Mao}

Class conceptualisation in China is not necessarily only tied to social stratification and economic divisions, which of course also exist and have done so in the past. It is also about the harmonious ordering of the social body as a tapestry of correct behaviours and placements. Such social ordering was corrupted in the recent history of the People's Republic of China (PRC). Mao Zedong's class analysis and social categorisation oscillated between self-serving political strategies, and the notion of class struggle became the basis for endless campaigns against enemies of the Party-State (Schram 1984). Maoist class struggle did not refer to active social divisions but to roughly applied concepts of blood lineage, and expediency. Mao's notion of class is thus inherited but deviates from its classical Chinese precedent. Jieji, the neologism for class in modern standard Chinese is taken from modern Japanese, which in turn was translated from classical Chinese. It denotes distinction and structural classification but in a different sense. While jieji originally connotes 'hierarchical degrees on a continuum' (Kuhn 1984: 17), it does not classify groups of people but mark their places in a given order. In its early form it points to a fixed order of aristocratic distinction, 'linked to a routinized system of political preferment' (Kuhn 1984: 17). The important point here is that classically jieji highlights distinction based on political preferment.

But though the image of jieji as fixed degrees in a continuum persisted, its actual reference changes in time. The use of jieji has its own history. For instance, 'by late imperial times, the meaning of $j i$ had shifted entirely away from inherited aristocratic status and was associated with the eighteenth-rank system of bureaucratic distinctions' 
(Kuhn 1984: 18). This suggests that since late imperial times (1368-1912) jieji was no longer a fixed system of distinction in China, as advancement in bureaucratic distinction through personal political effort, rather than through birthright, became the determining factor in social classification. It was not a system that relied on inherited social origins; but, while prioritising political preferment, it also presupposed, in fact, relied on, social mobility based on education and practices of personal as well as group cultivation. The economic factor only figured indirectly in this shifting grid of preferment and status, though that also became increasingly important. The jieji system of distinction was generally supplemented by the division of society into occupational status groups, such as the four categories of shi nong gong shang: scholar-gentry, agriculturalists, artisans, and merchants. If this latter socially hierarchical system was economically differentiated, it was so in terms of a universal economic priority determined by the State's fiscal interest rather than by individual or group wealth (Kuhn 1984: 20). When Liang Qichao first used the term in 1899 to introduce European thought on social and economic power through Japanese interpretation, he meant it as the gradient that separated society whilst binding it closely together (Liang quoted in Kuhn 1984: 20). This first 'modern' use of class is still more akin to a grading system rather than a social grouping based on economic status.

Mao's grasp and articulation of Chinese social relations in the twentieth century centered on class and class struggle. As an absolute principle it steered half a century of Chinese political and social life. This was a combination of the Marxist precept of economically determined class, and the shifting politically volatile grid of jieji, which was both exploitative and socially imagined. Its deployment was thus contingent and fraught with conceptual contradictions and political tension. That tension continues today, but the focus is on consumption of goods and the production of national wealth within a discourse of State legitimation, rather than on the incorporation of political doctrine into the self as an end and means. The self is still a political body, but the performance of class attributes supports the nation-State as an organisation, and not an ideological habitus.

\section{Post-Bourdieu}

In debates on class and social stratification outside the Chinese system, there is common reference to Pierre Bourdieu's theorisation of 'the habitus' (1984: 169). By situating 
discrete lifestyles and practices of cultural distinction in 'the social space' (1984: 169), Bourdieu's formulation, based on empirical sociological studies of twentieth century French class culture, retains the notion of structural change but redefines it as a process of social historical formation. The focus on the social space of culture and lifestyles highlights that sociocultural relations are cultivated, lived and embodied. It makes clear how they take on a particular form, which correlates with, but is not reducible to, economic capital. Bourdieu's theorisation, while offering insights into the social formation of French society at a given period, provides at the same time a useful analytical grid for thinking about the interrelation between particular cultural forms and long term sociohistorical structural change. Its emphasis on the importance of social origins as a determining factor in cultural distinction, and its relative reliance on the historical longue durée, however, makes it unable to serve as a complete model for understanding post-socialist Chinese social formation and cultural distinction. So, this collection goes beyond Bourdieu in that while we recognise the importance of his work for drawing attention to the cultural, we must insist on the specificity of the local conditions of Chinese social systems and political expedients in bringing the cultural to a new fruition.

Post-socialist Chinese social restratification, for instance, as one direct consequence of the Party-State's reform policy, demonstrates dramatic time compression - a condition neither understood nor elaborated in Bourdieu's model. Problems of disadvantage and inequality are to be expected in accelerated development. The Chinese State offers normative social and cultural programs of betterment as a palliative to disadvantage, such as the various campaigns (in the 1980s, 1990s and through till today) to cultivate spiritual quality of the population at large, and the popularisation of the vision for a 'harmonious society' based on the coming-to-be of a middleclass-centered society, which has been the key rhetorical impulse to policy design in the present century.

In recent academic work on middleclass formation and its significance in China, very few analysts find that the structural foundations of a middleclass-centered society are in place (Lu Xueyi 2002). But many critics conclude that those who loosely fit the descriptor of the new one-class are largely urban, and that a majority is concentrated in State-controlled professions and institutions, surpassing the more visible management personnel or white-collar workers for foreign cooperations and private entrepreneurs (Li 
Chunlin 2005: 510). The implications of this 'middleclass formation with Chinese characteristics' are two-fold. First, the concentration of metropolitans in key, often State-related, professions, makes clear again that the emergence of middle class interests in post-socialist urban China is closely tied to the State. Second, as insiders of economic, governing or professional bodies they can more easily influence government policies and initiatives, and as a consequence move their own emerging collective interests and aspirations into the social mainstream. Their envisioned function is thus exemplary to society at large, even though they also represent discrete clusters of political or social interests.

What also emerges from these observations is that this body of 'class' influence is most obviously demonstrated in the cultural arena. Urban avant-gardes and trend-setterssuch as elite media industry personnel, government cultural agency workers, Statesector and multinational business professionals - control the soft media. They lead social and cultural fashions, and have the means to spread their attitudes and value systems to the whole society. Under such circumstances, though their numbers are limited, and their cultural values cannot function to provide comprehensive social cohesion, nevertheless they represent an expansive cultural tendency that operates as a political and social force for the maintenance of the State ( $\operatorname{Li} 2005: 511)$.

\section{Contributions to the special issue}

This special issue seeks to locate and describe how the newly forming class interests of the wealthy and aspirational emerge both as exemplars and as aspirants to the security of the new utopia. The papers include contributions covering aspects of post-reform ${ }^{1}$ social stratification and cultural formation, and which reflect on the significance of reinvention and resurgence of class discourses in the realms of culture, social consciousness, and commercial practice. The issues are dealt with both at the macropolitical and the micro-everyday level. Together the papers shed light on specific configurations of the category of class and the role of status in a post-Bourdieu and post-Mao context.

\footnotetext{
${ }^{1}$ Whilst the reform era started after the death of Mao in 1976 and took distinctive shape as a result of new economic policies under Deng Xiaoping from 1978, post-reform is more nebulous: it refers to the midlate 1990 s and the $2000 \mathrm{~s}$ - as the results of change on the organisation of daily life become more apparent. For a short contextual overview of this era and its implications for 'class-ness' and gender, see Donald and Zheng (2009: 501-3).
} 
In 'Life Spectacles: Media, Business Synergy and Affective Work in Neoliberal China,' Hai Ren examines the way in which Chinese media communicate the meanings of everyday life. He also discusses how operators of theme parks, theme shopping malls, and residential communities deploy spatial planning and engineering techniques to train their users to behave like appropriate citizens in an ideal one-class society. Ren makes clear that his analysis is set against the backdrop of China's gaige kaifang (reform and opening) policy since the late 1970s, which extracted individuals from the social institutions developed under socialism and re-embedded them within a new sociopolitical system. The essay demonstrates that within the social space by which the State's middle/one class project is envisioned, not only are the institutional structures of socialist China disappearing but forms of practical knowledge, common sense, and guiding norms associated with socialism are no longer legitimate tools of empowerment.

Nyiri Pál's cultural anthropological study, 'From Starbucks to Carrefour: Consumer Boycotts, Nationalism and Taste in Contemporary China,' probes the motivations behind the series of nationwide consumer boycott campaigns against several foreign companies in the 2000s. The article discusses the dynamics of consumer boycotts and asks whether, beyond being a vehicle of nationalism, the emerging politics of consumption is also becoming a tool of expressing emergent class taste. Nyiri observes that the Chinese case is different from the cultural politics of the Soviet Union or Eastern Europe under state socialism, where cultural protectionism tended to be a preserve of the high priests of high culture. In China, attempts to link a highbrow discourse of taste with cultural protectionism find less resonance with nationalists, and their effects are harder to predict. In Nyiri's analysis, the recent proliferation of consumer boycotts is part and parcel of the wave of popular nationalism in China that is subject to the complex symbiosis between market and State in which the official discourse of the nation is coopted in commercial advertising and percolates down to Internet bulletin boards. Nyiri concludes that, although there is ample evidence of state manipulation and control of consumer nationalism, the boycotts have been grassroots movements. The politics of consumption are moving to the centre of Chinese nationalism; and they provide an arena for emerging discourses of taste that allow individuals to sidestep or modify dominant versions of the State and the nation.

Luigi Tomba's essay looks directly at the production of a Chinese middle class during 
the Reform period and the factors that have contributed to it. He highlights the role of a growing group of big spenders and consumers in China's economic growth and political stability. Tomba argues that a dramatic status enhancement for wage-earning Chinese professionals has been among the major determinants of social change in the late 1990s and that this process happened despite the market more than because of it. Tomba's essay shows that the development of a high-consuming urban society has been as much the outcome of the social engineering project of the contemporary reformist state and its agencies as it has been a consequence of the opening up of the economy and society.

In the section 'New Perspectives Reports,' our two authors engage directly with cultural debates in PRC on class taste, the media and social change. Their cultural commentaries reflect on post-reform social restratification and the resurgence of class culture. In his case report and analysis 'Mapping Society: the New Function of Print Media in Mainland China - the Case of New Weekly,' Xiaolu Wang links the changing aims and functions of Chinese print media today with the conceptual and social changes of PRC intellectuals as a knowledge class. New Weekly is one of the most influential illustrated Chinese magazines focusing on social issues and phenomena. Analysing the magazine's design and content, the author argues that the taste-based innovations of new Chinese print media reflect the changes in social formation and conceptual shifts of the intellectual class.

Songyu Lin's 'Mix and Match or Confusion?: Middleclass Taste in China' also looks into the contested terrain of taste formation in the popular media. Examining in particular the so-called fiction of petit bourgeoisie sentiments, popular among whitecollared workers and young aspirants to new iterations of tasteful lifestyles, Lin points out that cultural trends and taste patterns refer also to the influence and interests of old cultural traditions, post-authoritarian polity and the new State-capitalist economy. The mix and match, or flagrant confusion, in matters of class and taste, testify not only to the obvious spiritual homelessness of a post-socialist society, but more importantly foreground the contest for social and cultural leadership in the one-class or middle-class utopia. Lin concurs with some of the leading Chinese cultural critics that we are witnessing the emergence of a taste elite, comprising the new generation of highly educated youth, who seek to benefit from post-Reform economy and polity. 
In all these papers, the use of the term middle class is strategic rather than absolute, insofar as the term already refers to an empty categorisation, and a shifting set of practices, habits and aspirations. The use of the term is nonetheless helpful in that, although it does not indicate a class structure or indeed class habits familiar to other societies (or not necessarily), it aptly captures both the deployment and elision of class consciousness in China post-Mao.

\section{Acknowledgements}

This introduction and the special issue of PORTAL Journal of Multidisciplinary International Studies is a result of a funding grant from the Australian Research Council, 2003-2005: 'The Making of Middle-Class Taste: Reading, Tourism, and Educational Choices in Urban China.' Both authors thank the respondents in that work, which is further reported in articles we have written on education, print culture and film (see, for example, Donald and Zheng 2008 and 2009). Donald would also like to thank Jerome Silbergeld for his hospitality and an illuminating conversation on class and politics that took place in Princeton, November 2009.

\section{Reference List}

Bourdieu, P. 1984, Distinction: A Social Critique of the Judgement of Taste, Routledge, London.

Chen, Guanren \& Yi Yan. 2004, Zhongguo zhongchanzhe diaoca (Investigations of the Chinese Middleclass), Tuanjie chubanshe, Beijing.

Donald, S. H. \& Yi Zheng. 2008, 'Richer than Before-The Cultivation of Middleclass Taste,' in The New Rich in China: Future Rulers, Present Lives, (ed.) D. G. S. Goodman, Routledge, New York and London, 71-82.

Donald, S.H. \& Yi Zheng. 2009, “A Taste of Class: Manuals for Becoming Woman,” positions: east asia cultures critique, vol. 17, no. 3, Winter, 489-521.

Doctoroff, T. 2005, Billions: Selling to the New Chinese Consumer, Palgrave Macmillan, New York.

Hofstadter, D. 2007, I Am a Strange Loop, Basic Books, New York.

Kuhn, P.A. 1984, 'Chinese Views of Social Classification,' in Class and Social Stratification in PostRevolution China, (ed.) J. L. Watson, Cambridge University Press, Cambridge, 16-28.

Li, Chunlin. 2005, Duanlie yu suibian: Dangdai Zhongguo shehui jiechen fenhua sizhen yanjiu [Cleavage and Fragment: an Empirical Analysis on the Social Stratification of Contemporary China], Social Science Academic Press, Beijing.

Lu, Xueyi (ed.) 2002, Research Report on the Current Social-Economic Structure of China, Chinese Academy of Social Sciences Press, Beijing.

Schram, S.R. 1984. 'Classes, Old and New, in Mao Zedong's Thought,' in Class and Social Stratification in Post-Revolution China, (ed.) J. L. Watson, Cambridge University Press, Cambridge, 29-55.

Stivens, M. 1998, 'Theorizing Gender, Power and Modernity in Affluent Asia,' in Gender and Power in Affluent Asia, (eds) K. Sen \& M. Stivens, Routledge, London, 1-34.

Wright, E.O. 2009, 'Understanding Class: Towards an Integrated Analytical Approach,' New Left Review, no. 60, December, 101-116. 